\title{
Screening Bactericidal Action of Cytoplasm Extract from Kumazasa Bamboo (Sasa veitchii) Leaf against Anti- biotics-Resistant Pathogens such as MRSA and VRE Strains
}

\author{
Shoichi Shirotake ${ }^{\star \#}$, Jutaro Nakamura\#, Akiko Kaneko, Eri Anabuki, and Naoto Shimizu \\ Department of Pharmaco-Therapeutics, Graduate School of Medicine, \\ Yokohama City University, Fuku'ura3-9, Knazawa-ku, Yokohama, 236-004, Japan \\ \# These authors contributed equally to this manuscript
}

\begin{abstract}
We aimed to develop a new treatment against antibiotic-resistant bacteria by focusing on cytoplasm of Kumazasa bamboo leaf. The cytoplasmic extract displays potent bactericidal action against Gram-positive bacteria such as Staphylococcus aureus, Enterococci and Streptococcus pneumoniae and also multi-antibiotic resistant MRSA (methicillin-resistant Staphylococcus aureus) and VRE (vancomycin-resistant Enterococci) strains. It induced bacteriolysis by firmly aggregating MSSA (methicillin-susceptible Staphylococcus aureus) and MRSA, and by lysis of VSE (vancomycin-susceptible Enterococci) and VRE. Clinical isolates of MRSA (30 strains in total) were susceptible to this extract, which gave MICs of Kumazasa-cytoplasmic extract ranging from 1.6 to $6.3 \%$. The antibacterial action was bactericidal on scanning electron microscopy (SEM) analysis. A synergistic effect of this extract with ampicillin (ABPC) was obviously observed in all MRSA strains. The synergistic effect with vancomycin (VCM) was observed against VRE. The combination with clarithromycin (CAM) or tetracycline (TC) additively enhanced the antibacterial activity of CAM against CAM-susceptible Enterococci strains, and also that of TC against TC-resistant VRE strains.
\end{abstract}

The present results should encourage research on antibacterial-hydrophilic ingredients derived from Kumazasa for use against antibiotic-resistant bacteria. The combination of Kumazasa-cytoplasmic extract with a cell wall synthesis inhibitor (ABPC or VCM) will be a highly efficient treatment for infections caused by multidrug-resistant MRSA and VRE strains.

Keywords: Kumazasa bamboo; Cytoplasm; Bactericidal action; Synergistic effect; Antibiotic; Multi-antibioic resistance; MRSA; VRE

\section{Introduction}

More than 50 years of widespread use of antibiotics has resulted in the gradual appearance of antibiotic-resistant bacteria (Noble et al., 1992; Bozdogan et al., 2003). Methicillin-resistant Staphylococcus aureus (MRSA, detection rate; ca 80\%) (Uehara et al., 2000) have acquired resistance due to the mecA gene, which encodes an altered penicillin-binding protein with reduced affinity for methicillin. In recent years, vancomycinresistant Enterococci (VRE) and vancomycin-resistant Staphy- lococcus aureus (VRSA) have appeared (detection rate for VRE; $20 \%$ or more of Enterococci in intensive care units in Europe and the U.S.A) (Frieden et al., 1993). One of the biggest therapeutic issues at the moment is the emergence of multiple antibiotic-resistant pathogenic bacteria which is very dangerous.

For thousands of years, plants have proved to be a rich source of biologically active compounds. Indeed throughout human history, plant extracts have been used to cure various chronic diseases. In recent years, numerous therapeutically useful drugs have been extracted from plants, (Kumarasamy et al., 2002; Coutinho et al., 2009) such as Aspirin, Kinin, Artemisinin, Taxol and Camptothecin. Plants have developed some unique antibacterial mechanisms against infection. Traditional medicines, such as mixtures of oriental herbs (Coutinho et al., 2009) and tea (Cho et al., 2008) were used as folk remedies to alleviate bacterial infections. Subsequent analysis has shown that these crude plant extracts contain biologically active components, such as essential oils (Duan and Zhao, 2009; Roller et al., 2009), flavonoids (Xu and Lee, 2001; Falcão-Silva et al., 2009), polyphenols (Cho et al., 2008) and alkaloids (Zuo et al., 2008), that display antibacterial activities (Pesewu et al., 2008; Shimizu et al., 2001). We have endeavored to identify and utilize hydrophilic antibacterial products from plant extracts for clinical applications.

In Japan, Kumazasa bamboo (Sasa veitchii) leaf have been used as SUSHI sheets or to package rice balls (known as CHIMAKI) to protect food from rotting due to the growth of bacteria. The traditional medicine from Kumazasa has a wide range of applications such as treatment of halitosis and body odor, stomatitis, gingivitis, bedsores, burns, hemorrhoids, cuts and purulent wounds. Organic solvent extracts (e.g., using diethyl ether) from leaves of Kumazasa (Sasa albo-marginata) were reported to possess antimicrobial activity against bacteria, fungi,

\footnotetext{
*Corresponding author: Shoichi Shirotake, Department of Pharmaco-Therapeutics, Graduate School of Medicine, Yokohama City University, Fuku'ura3-9, Knazawa-ku, Yokohama, 236-004, Japan, E-mail: shirophd@med.yokohama-cu.ac.jp
}

Received September 17, 2009; Accepted October 08, 2009; Published October 09, 2009

Citation: Shirotake S, Nakamura J, Kaneko A, Anabuki E, Shimizu N (2009) Screening Bactericidal Action of Cytoplasm Extract from Kumazasa Bamboo (Sasa veitchii) Leaf against Antibiotics-Resistant Pathogens such as MRSA and VRE Strains. J Bioequiv Availab 1: 080085. doi:10.4172/jbb.1000012

Copyright: () 2009 Shirotake S, et al. This is an open-access article distributed under the terms of the Creative Commons Attribution License, which permits unrestricted use, distribution, and reproduction in any medium, provided the original author and source are credited. 


\title{
Journal of Bioequivalence \& Bioavailability - Open Access
}

\author{
JBB/Vol.1 September-October 2009
}
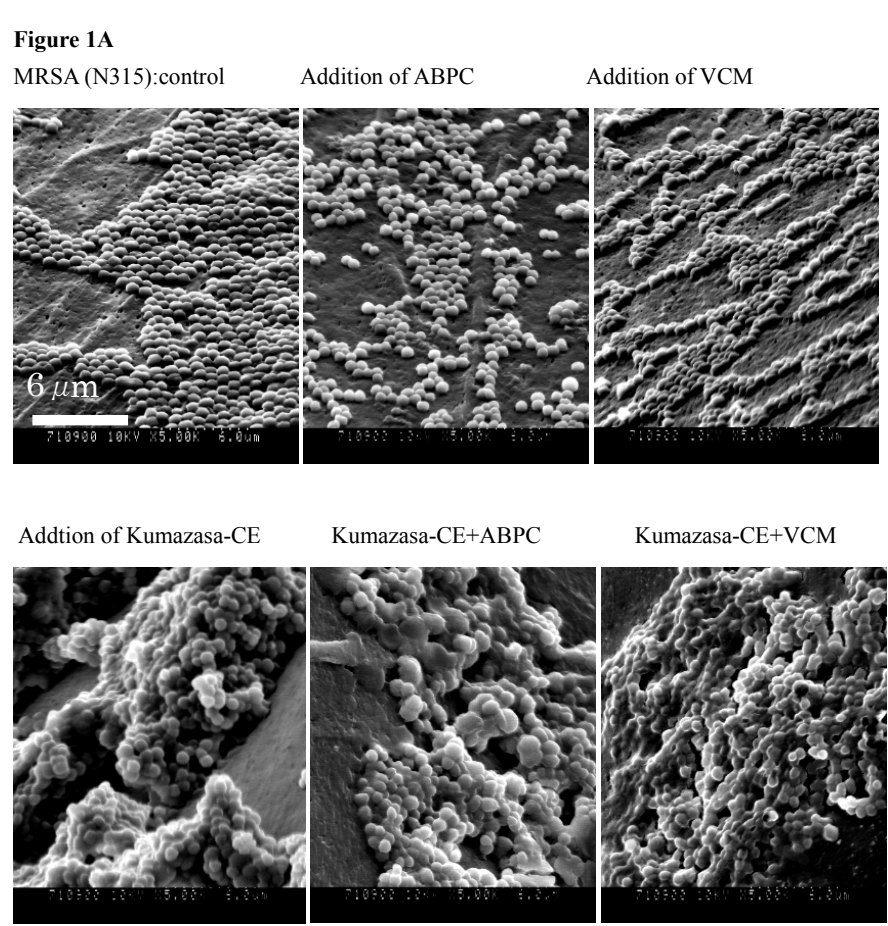

Kumazasa-CE+ABPC

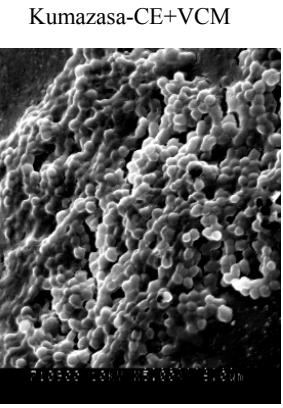

Figure 1B

$\operatorname{VRE}(12201)$ : control Addition of ABPC

Addition of $\mathrm{VCM}$
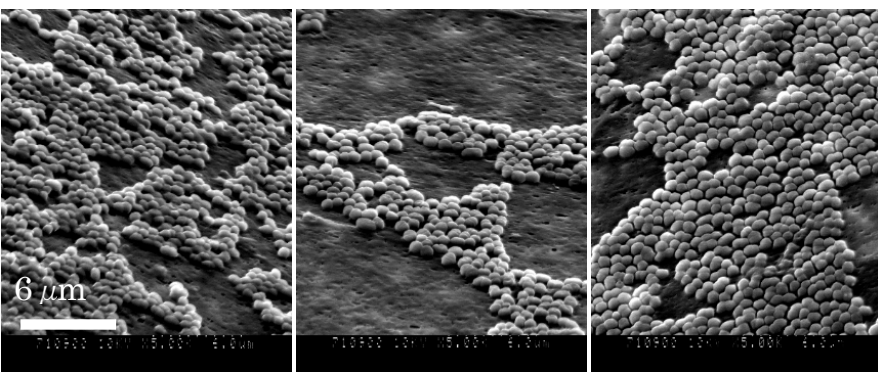

Addtion of Kumazasa-CE

Kumazasa-CE $+\mathrm{ABPC}$
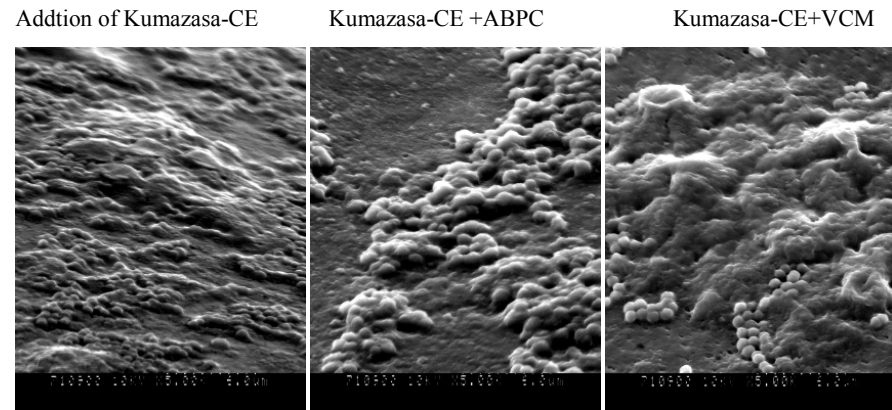

Figure1: Morphological influence by Kumazasa-cytoplasmic extract alone, and by combination with ampicillin or vancomycin against multiple antibiotic-resistant bacteria on SEM image(x5000).

Figure 1A: Morphological influence against methicillin-resistant Staphylococcus aureus (MRSA:N315). Kumazasa-CE (Kumazasa cytoplasmic extract) induced firm aggregation of MRSA. A combination with ampicillin (ABPC) resulted in firm aggregation of MRSA and bacteriolysis from mycelia caking change.

Figure 1B: Morphological influence against vancomycin-resistant Enterococci (VRE: NCTC12201). Kumazasa-CE (Kumazasa-cytoplasmic extract) showed bacteriolytic action against VRE. and yeast (Chuyen et al., 1982). To date, no studies have been conducted to investigate the antibacterial activity in the organic extracts against antibiotic-resistant bacterial strains. Herein, we examine the cytoplasmic extract from Kumazasa leaf in terms of its antibacterial activity against multidrug-resistant pathogens.

\section{Materials and Methods}

\section{Cytoplasmic Extraction from Kumazasa Bamboo Leaf}

The cytoplasm hydrophilic extraction was obtained by removing resin and lignin from green leaves of striped Kumazasa (Sasa veitchii), as following. Fresh Kumazasa leaves were crushed and homogenized by a mixer, then steeped in a $3 \% \mathrm{NaOH}$ solution at room temperature overnight (the cell membrane was destroyed by alkaline hydrolysis). The $\mathrm{pH}$ value of the solution was adjusted to 4 , by dropping $\mathrm{H}_{2} \mathrm{SO}_{4}$ solution, and the residue was collected by centrifugation (x15000rpm), then the residue was dissolved at concentration of $40 \mathrm{mg} / \mathrm{ml}$ in warm distilledwater as a green-colloidal solution, then the $\mathrm{pH}$ value was adjusted to 7.4, by dropping $\mathrm{NaOH}$ solution (cytoplasmic crude extraction).

\section{Bacterial Strains}

Methicillin-susceptible Staphylococcus aureus (MSSA); ATCC6538 and JCM2874, Methicillin-resistant Staphylococcus aureus (MRSA); JCM8703 and N315 GTC01187, Vancomycin-sensitive Enterococcus faecium (VSE); JCM5804, Vancomycin-resistant Enterococcus faecalis (VRE); GTC02000 and NCTC12201, Clinical isolates of MRSA (30 isolates) were provided by Yokohama-City University Hospital (Yokohama, Japan).

\section{Determination of Antibacterial Activity and Combination} Effect with Antibiotic

The minimum inhibitory concentrations (MICs) of Kumazasa medicine were determined by the microbroth dilution methods (National Committee for Clinical Laboratory Standards Institute, 1997). A dilute suspension of bacteria was inoculated into each well of a 96-well microplate, and the range of Kumazasacytoplasmic extract was $1.25 \%$ to $0.2 \%$ in the MH broth (Difco.). The final inoculum of bactera was approximately $7.5 \times 10^{4}$ cells/ well by MacFarland. MBCs (Peterson and Shanholzer, 1997) were defined as the lowest concentration of antimicrobial agent where was no bacterial growth on LB agar plates (Difco.).

The antibacterial effects of a combination of antibiotics and Kumazasa was assessed by the checkerboard method (White et al., 1996).

\section{Morphological Analysis of MRSA and VRE}

MRSA and VRE were incubated in MH broth with or without Kumazasa medicine and/or antibiotics for $24 \mathrm{hr}$. After incubation, culture suspension was filtered using Nuclepore Track-Etch membrane of pore size 0.1 um (Whatman Inc, Clifton, NJ USA). Morphological changes of MRSA and VRE were assessed by scanning electron microscopy (type:S-800, Hitachi Corp., Tokyo, Japan).

\section{Results and Discussion}

Plants have developed unique antibacterial mechanisms for protection against infection. In this study, we focused on anti- 


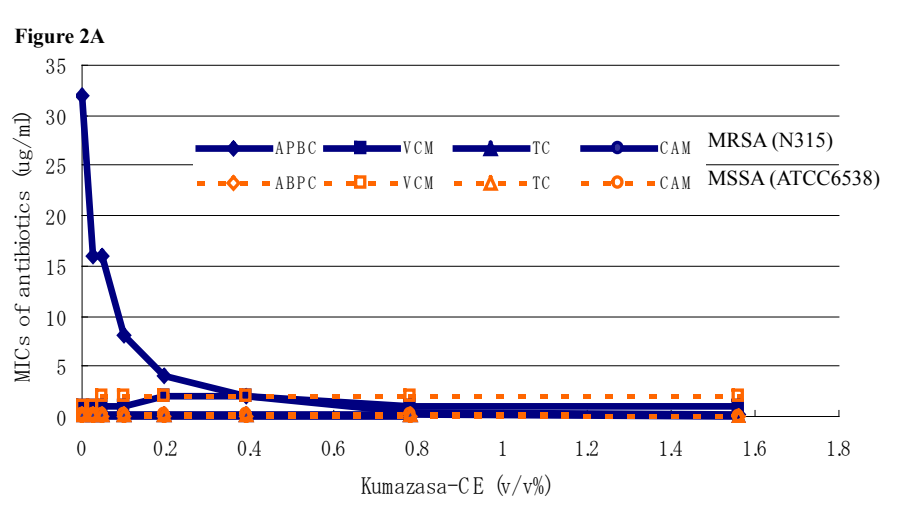

Figure 2B
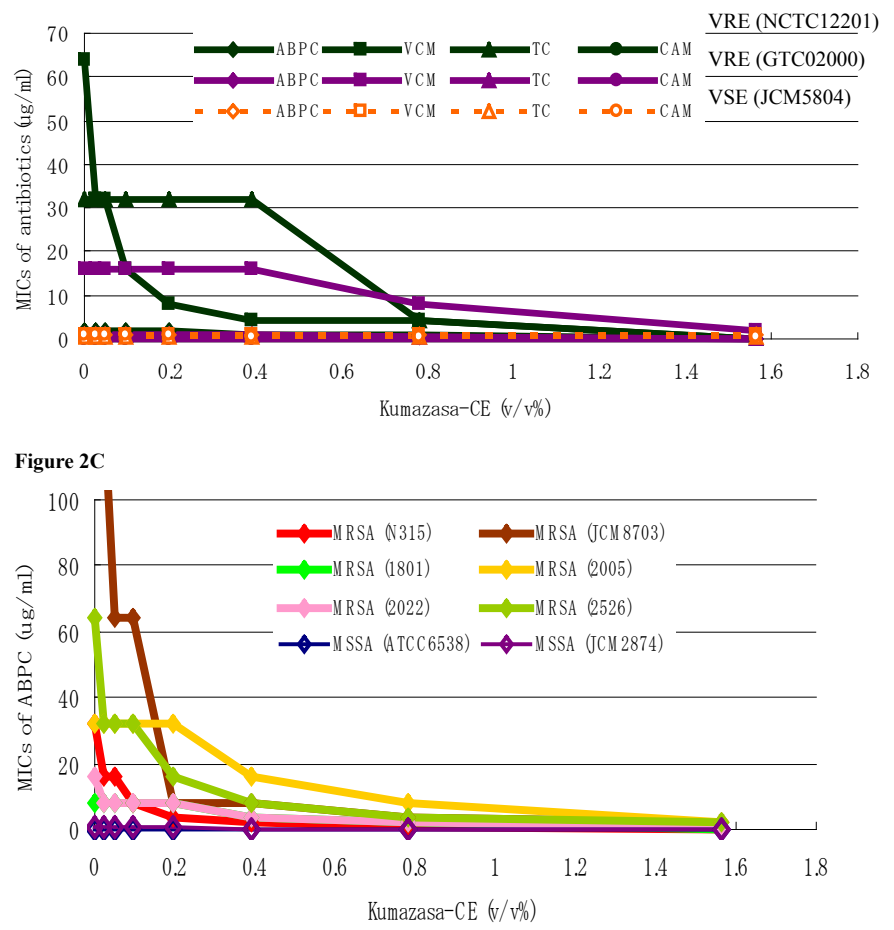

Figure 2: Synergistic effect of cytoplasmic extract from Kumazasa with antibiotics against Staphylococcus aureus strains and Enterococci strains.

Figure 2A: Synergistic effect of Kumazasa-CE (Kumazasa cytoplasmic extract) with ampicillin (ABPC) against methicillinresistant Staphylococcus aureus (MRSA:N315). The antibacterial activity of vancomycin (VCM) and tetracycline (TC) against MRSA(N315) was not affected by a combination of Kumazasa$\mathrm{CE}$, because of the susceptibility to each antibiotic. A combination effect between Kumazasa-CE and clarithromycin (CAM)

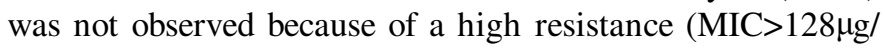
$\mathrm{ml}$ ). Such synergistic effect was not observed on methicillinsusceptible Staphylococcus aureus (MSSA; ATCC6538). Each tested by triplicate.

Figure 2B: Synergistic effect of Kumazasa-CE with vancomycin (VCM) against vancomycin-resistant Enterococci (VRE:NCTC12201), and additive effect against VRE(GTC02000) which is intermediate-resistant to VCM. The antibacterial activity of tetracycline (TC) against VRE(NCTC12201) additively decreased on a combination of Kumazasa-CE, but not affected against VRE(GTC02000) because of susceptibility. The antimicrobacterial activity of ampicillin (ABPC) and clarithromycin (CAM) was not affected by a combination of Kumazasa-CE. Such synergistic effect was not observed on vancomycin-susceptible Enterococci (VSE:JCM5804). Each tested by triplicate.

Figure 2C: Synergistic effect of Kumazasa-CE with ABPC against clincal isolated methicillin-resistant Staphylococcus aureus strains (MRSA). Synergistic effect was observed against all MRSA strains (clinical isolated 30 strains). Each tested by triplicate.

bacterial action in cytoplasm of Kumazasa leaf. The antimicrobial activity (as MIC) of cytoplasmic extract from Kumazasa or each antibiotic (ampicillin: ABPC, vancomycin: VCM, clarithromycin: CAM, or tetracycline: TC) was measured against both Gram-positive and Gram-negative microbes (in Table 1). The Kumazasa-cytoplasmic extract (Kumazasa-CE) displayed a markedly potent antibacterial activity against Gram-positive bacteria such as Staphylococcus aureus, Enterococci and Streptococcus pneumoniae (MICs; 0.8-6.3 (v/v) \%, 1\% KumazasaCE contained $0.4 \mathrm{mg}$ of the dry extract). The antibacterial activity against Gram-positive bacteria is much stronger than that against Gram-negative bacteria such as E.coli or P.aeruginosa (MICs of Kumazasa medicine $>25 \%$ in both cases) (in Table 1), because of the hydrophilic property of this extract. The Kumazasa-CE displayed strong antimicrobial activity (MICs; 0.8-6.3 (v/v) \%) against both antibiotic-susceptible and -resistant Staphylococcus aureus and Enterococci strains, such as MSSA and MRSA, or VSE and VRE, respectively. Furthermore, this extract is also effective against multi-antibiotic resistant MRSA and VRE, although MRSA and VRE were simultaneously resistant to many antibiotics (in Table 1). Clinical isolates of MRSA (30 strains in total) were also tested, which gave MICs of Kumazasa-CE ranging from 1.6 to $6.3 \%$. The MICs were compared with 16 to 128 times dilution of Kumazasa-CE, and the MIC value was corresponded to the Minimum bactericidal concentration value (MBC (Peterson and Shanholzer, 1997)). Scanning electron microscopy (SEM) images clearly showed that this extract induces firm aggregation of MRSA (in Fig.1A). This firm aggregation is a characteristic action to Staphylococcus aureus. Using VRE (NCTC12201), bacteriolysis was clearly observed after addition of this extract alone, but the firm aggregation was not evident from the SEM images (in Fig.1B). SEM analysis unmistakably showed the bacteriolytic action of this extract against VRE (in Fig.1B). Such antibacterial action was clear against also each antibiotic-susceptible strain on SEM image(data not shown). The cytoplasmic extract from Kumazasa displays surely bactericidal action against Gram-positive strains and also the multiple antibiotic-resistant bacteria as MRSA and VRE strains.

The synergistic effect was examined by checkerboard methods (White et al., 1996) in combination between this cytoplasmic extract and antibiotics (ABPC, VCM, CAM, and TC). ABPC and VCM inhibit a synthesis of bacterial cell-wall on binding to the target site on the cell-wall, while CAM and TC inhibit a protein synthesis on binding target enzyme inside of cell. The combination effect with antibiotic was evaluated by fractional inhibitory concentration (FIC) index in the method. FIC index $\leqq 0.5$ were judged to be a synergistic effect; $0.5<$ FIC indexi $\leqq 1.0$ for an additive effect; $1.0<$ FIC index $\leqq 2.0$ no effect, as shown in Table 2. 


\section{Journal of Bioequivalence \& Bioavailability - Open Access \\ JBB/Vol.1 September-October 2009}

\begin{tabular}{|c|c|c|c|c|c|c|}
\hline & \multirow[b]{2}{*}{ strain } & \multicolumn{3}{|c|}{ MIC } & \multirow[b]{2}{*}{$\begin{array}{c}\text { CAM } \\
(\mu \mathrm{g} / \mathrm{ml})\end{array}$} & \multirow[b]{2}{*}{$\begin{array}{c}\text { TC } \\
(\mu \mathrm{g} / \mathrm{ml})\end{array}$} \\
\hline & & $\begin{array}{c}\text { Kumazasa- cytoplasmic } \\
\text { Extraction }(\mu \mathrm{g} / \mathrm{ml})\end{array}$ & $\begin{array}{l}\text { ABPC } \\
(\mu \mathrm{g} / \mathrm{ml})\end{array}$ & $\begin{array}{l}\text { VCM } \\
(\mu \mathrm{g} / \mathrm{ml})\end{array}$ & & \\
\hline \multirow{2}{*}{ MSSA } & ATCC6538 & 640 & 0.063 & 1 & 0.063 & 0.125 \\
\hline & JCM2874 & 1240 & 0.5 & 1 & 0.25 & 0.5 \\
\hline \multirow{2}{*}{ MRSA } & N315 & 320 & 32 & 1 & $>128$ & 0.125 \\
\hline & JCM8703 & 640 & $>128$ & 2 & $>128$ & 64 \\
\hline \multirow{4}{*}{$\begin{array}{l}\text { MRSA } \\
\text { (clinical } \\
\text { isolate) }\end{array}$} & 2005 & 1240 & 32 & 1 & $>128$ & 16 \\
\hline & 2526 & 2520 & 64 & 2 & $>128$ & 0.5 \\
\hline & 1801 & 640 & 8 & 2 & $>128$ & 128 \\
\hline & 2022 & 1240 & 16 & 2 & $>128$ & 128 \\
\hline VSE & JCM5804 & 2520 & 1 & 1 & 1 & 0.5 \\
\hline \multirow{2}{*}{ VRE } & GTC02000 & 1240 & 1 & 16 & 0.063 & 0.5 \\
\hline & NCTC12201 & 640 & 2 & 64 & $>128$ & 32 \\
\hline S.pneumoniae & ATCC262 & 320 & 0.03 & 0.06 & 0.03 & 0.25 \\
\hline E. coli & ATCC12923 & 10000 & 8 & $>128$ & $>128$ & 1 \\
\hline P. aeruginosa & ATCC12924 & 10000 & $>128$ & $>128$ & $>128$ & 2 \\
\hline
\end{tabular}

MIC of Kumazasa-cytoplasmic extraction was calculated as the concentration of the dry crude-extract.

MIC....susce, $p$ tible, MIC ...intermediate resistant, MIC....resistant (by CLSI; MIC Interpretive Standards), Each tested by triplicate.

MSSA:methicillin-susceptible Staphylococcus aureus.

MRAS:methicillin-resistant Staphylococcus aureus.

VSE:vancomycin-susceptible Enterococci.

VRE:vancomycin-resistant Enterococci.

ABPC:ampicillin, VCM:vancomycin, CAM:clarithromycin, TC: tetracycline.

Table 1: The antibacterial activity of cytoplasmic extract from Kumazasa and antibiotics against antibiotic-susceptible and -resistant bacteria.

\begin{tabular}{|l|c|c|c|c|c|c|c|c|c|}
\hline \multirow{2}{*}{ strain } & antibiotic & \multicolumn{2}{|c|}{ ABPC } & \multicolumn{2}{c|}{ VCM } & \multicolumn{2}{c|}{ CAM } & \multicolumn{2}{c|}{ TC } \\
\cline { 2 - 11 } & & FIC & effect & FIC & effect & FIC & effect & FIC & effect \\
\hline \multirow{3}{*}{ MSSA } & 6538 & 1.02 & No effect & 1.02 & No effect & 1 & No effect & 1.02 & No effect \\
\cline { 2 - 11 } & 2874 & 0.63 & Additive & 1.01 & No effect & 1 & No effect & 1.01 & No effect \\
\hline \multirow{5}{*}{ MRSA } & N315 & 0.38 & Synergy & 1.03 & No effect & $*$ & No effect & 1.03 & No effect \\
\cline { 2 - 11 } & 8703 & 0.16 & Synergy & 1.02 & No effect & $*$ & No effect & 0.56 & Additive \\
\cline { 2 - 11 } & 2005 & 0.5 & Synergy & 1.01 & No effect & $*$ & No effect & 0.56 & Additive \\
\cline { 2 - 11 } & 2526 & 0.19 & Synergy & 1 & No effect & $*$ & No effect & 1 & No effect \\
\cline { 2 - 11 } & 1801 & 0.5 & Synergy & 1.02 & No effect & $*$ & No effect & 1.02 & No effect \\
\cline { 2 - 11 } & 2022 & 0.38 & Synergy & 1.01 & No effect & $*$ & No effect & 1.01 & No effect \\
\hline VSE & 5804 & 1 & No effect & 1 & No effect & 0.56 & Additive & 1 & No effect \\
\hline \multirow{3}{*}{ VRE } & 02000 & 0.63 & Additive & 0.56 & Additive & 0.56 & Additive & 0.63 & Additive \\
\cline { 2 - 11 } & 12201 & 0.75 & Additive & 0.25 & Synergy & $*$ & No effect & 0.63 & Additive \\
\hline
\end{tabular}

Fractional inhibitory concentration index value (FIC) was calculated by the checkerboard method. ${ }^{20)}$

Synergy defined as an FIC of $<0.5$, Additive as $0.5<$ FIC $<1$; Each tested by triplicate.

*Not calculated because of a high resistance (MIC $>128 \mu \mathrm{g} / \mathrm{ml}$ ).

MSSA:methicillin-susceptible Staphylococcus aureus.

MRAS:methicillin-resistant Staphylococcus aureus.

VSE:vancomycin-susceptible Enterococci.

VRE:vancomycin-resistant Enterococci.

ABPC:ampicillin, VCM:vancomycin, CAM:clarithromycin, TC:tetracycline.

Table 2: Fractional inhibitory concentration index and Synergistic evaluation on a combination of cytoplasmic extract from Kumazasa with antibiotics against MSSA, MRSA, VSE, and VRE. 


\section{Journal of Bioequivalence \& Bioavailability - Open Access \\ JBB/Vol.1 September-October 2009}

The combination with $\mathrm{ABPC}$ strengthened the antibacterial activity of ABPC against MRSA, since MICs of ABPC diminished in a dose-dependent manner (Fig. 2). The FIC index values were under 0.5 indicating the synergistic effect on antibacterial activity of ABPC. Although the synergistic effect of the components in tea, such as catechins, flavonoids and polyphenols, with $\beta$-lactam antibiotic against MRSA strains has been reported, (Cho et al., 2008; Xu and Lee, 2001; Falcão-Silva et al., 2009) the precise-synergistic mechanism remained unclear. As observed from the present SEM images (in Fig.1A), the combination with ABPC resulted in firm aggregation of MRSA, which then triggered bacteriolysis from mycelia caking change. Our SEM analysis indicated that the synergistic effect is derived from a combination of both bacterial aggregation, mediated by this extract, and morphological transformation, mediated by ABPC. A combination of this extract with VCM synergistically enhanced the antimicrobial activity of VCM against VRE, but did not affect against susceptible Enterococci (Fig.2 and Table2). Moreover, the observed bacteriolytic activity against VRE (NCTC122201) by co-administration of VCM and this extract was greater than anticipated from the sum of the antibacterial activities of VCM or the Kumazasa-CE alone (i.e., a non additive effect). This synergistic effect with VCM is a novel finding. The combination effect was not observed against the strains susceptible to ABPC or VCM (in Table 2). Interestingly, the efficacy of this extract is closely related to an inhibitor of bacterial cell-wall synthesis on multi-antibiotic resistant MRSA and VRE strains.

The synergistic effect on CAM could not be measured because of the strong resistance of MRSA to CAM (MIC >128 $\mu \mathrm{g} / \mathrm{ml})$. The antibacterial activity of CAM was increased by half upon using $0.8 \%$ of the Kumazasa-CE against MSSA susceptible to CAM, showing an additive effect. However, the extracts at concentrations $0-0.4 \%$ did affect the MIC values of CAM. Similarly, the antimicrobial activity of CAM was enhanced by a combination of this extract against VSE and VRE(GTC0200), which are susceptible to CAM. However, such combination effect could not be detected against VRE(12201), which is strongly resistant to CAM. This extract additively enhanced the antibacterial activity of TC against MRSA (JCM8703, and clinical isolate 2005) and VRE (GTC02000 and NCTC12201) in checkerboard method, however it was not obtained against TC-highly resistant and susceptible Staphylococcus aureus strains (in Tables 1 and 2). The target sites for both CAM and TC are intracellular, and the resistant mechanism consists of a modulation on target sites and an acceleration of efflux pump. Herbal extracts were reported to reinforces synergistically the antibacterial activity by inhibition of the efflux pump for antibiotics (Rosato et al., 2007; Lee et al., 2008; Coutinho et al., 2009). No such synergistic effect between this extract and CAM and/or TC was observed from the SEM images or from the fractional inhibitory concentrations determined using the checkerboard method. The absence of synergistic action in this extract is presumably because the target sites for both CAM and TC are intracellular.

Although there is no question concerning the observed synergistic effect between the Kumazasa-cytoplasmic extract and ABPC or VCM against antibiotic-resistant bacteria (e.g., MRSA or VRE), the precise mechanism of action needs further study. Furthermore, heat treatment of this Kumazasa extract using an autoclave had no effect on the observed antibacterial activity and the synergistic effect (data not shown). Therefore, the active components are heat stable. Kumazasa leaf containes many ingredients, as minerals, vitamins, polysaccharides, flavonoids, and other macromolecules (Chuyen et al., 1982). The present results should encourage research on antibacterial-hydrophilic ingredients derived from Kumazasa for use against antibioticresistant pathogen.

We conclude that the cytoplasmic extract from Kumazasa leaf displayed the unique bactericidal action against multi-antibiotic resistant MRSA and VRE strains, and that the combination with a cell wall synthesis inhibitor (ABPC or VCM) will be a highly efficient treatment for infections caused by multidrug-resistant MRSA and VRE strains.

\section{Acknowledgements}

The clinical isolated MRSA strains were kindly provided by T.Mituda, Yokohama City Univ. Hospital. The authors thank N.Sasatu, Tokyo Pharmacy Univ., and T.Toyo' oka, Sizuoka Univ. for valuable comments, and N.Hotoki for technical assistance. This work was supported by Grants-Aid for Scientific Research (No. 20659069 to S.S.) from the Ministry of Education, Culture, Sports, Science and Technology of Japan, and partly by the Grant for 2008 StrategicResearch Project (No. K20028) of Yokohama City Univ., Japan.

\section{Author Contributions}

S.S. led the discovery, designed and extraction from Kumazasa-CE, J.N. and A.K. measured antibacterial activity. E.A and N.S. coordinated synergistic effect and SEM analyses.

\section{References}

1. Bozdogan B, Esel D, Whitener C, Browne FA, Appelbaum PC (2003) Antibacterial susceptibility of a vancomycin-resistant Staphylococcus aureus strain isolated at the Hershey Medical Cemter. J Antimicro Chemother 52: 864-868. " CrossRef » Pubmed » Google Scholar

2. Cho YS, Schiller NL, Oh KH (2008) Antibacterial effects of green tea polyphenols on clinical isolates of methicillin-resistant Staphylococcus aureus. Curr Microbiol 57: 542-546. " CrossRef » Pubmed » Google Scholar

3. Chuyen NV, Kurata T, Kato H, Fujimaki M (1982) Antimicrobial Activity of Kumazasa (Sasa albo-marginata). Argric Biol Chem 46: 971-978. » CrossRef » Google Scholar

4. Coutinho HD, Costa JG, Lima EO, Falcão-Silva VS, Siqueira JP Jr (2009) Herbal therapy associated with antibiotic activity against methicillin-resistant Staphylococcus aureus by Tumera ulmifolia L. BMC Complement Altern Med 8: 9-13. " CrossRef » Pubmed » Google Scholar

5. Coutinho HDW, Gosta JGM, Lima EO, Flacao-Silva VS, Junior JPS (2009) Herbal therapy associated with antibiotic therapy: potentiation of the antibiotic activity against methicillin-resistant Staphylococcus aureus by Turnea ulmifolis L. BMC Complementary and Alternative Med 9: 1-3.

6. Duan J, Zhao Y (2009) Antimicrobial efficiency of essential oil and freeze-thaw treatments against Escherichia coli O157:H7 and Salmonella enterica Ser. Enteritidis in strawberry juice. J Food Sci 74: M131-137. » CrossRef » Pubmed " Google Scholar 


\section{Journal of Bioequivalence \& Bioavailability - Open Access \\ JBB/Vol.1 September-October 2009}

7. Falcão-Silva VS, Silva DA, Souza MD, Siqueira-Junior JP (2009) Modulation of grug resistance in Staphylococcus aureus by a kaempferol glycoside from herissantia tibae (malvaceae). Phytother Res. » CrossRef » Google Scholar

8. Frieden TR, Munsiff SS, Low DE, Willey BM, Williams G, et al. (1993) Emergence of vancomycin-resistant Enterococci in New York City. Lancet 342: 76-79. CrossRef » Pubmed " Google Scholar

9. Hiramatus K, Aritaka N, Hanaki H, Kawasaki S, Hosoda Y, et al. (1997) Dissemination in Japanese hospitals of strains of Staphylococcus aureus heterogeneously resistant to vancomycin. Lancet 350: 1670-1673. „ " CrossRef » Pubmed " Google Scholar

10. Kumarasamy Y, Cox PJ, Jaspars M, Nahar L, Sarker SD (2002) Screening seeds of Scottish plants for antibacterial activity. J Ethnopharmacol 83: 73-77. CrossRef » Pubmed " Google Scholar

11. Lee YS, Kang OW, Choi JG, Oh YC, Chae HS, et al. (2008) Synergistic effects of the combination of galangin with gentamicin against methicillin-rtesistant Staphylococcus aureus. J Microbiol 46: 283-288. » CrossRef » Pubmed » Google Scholar

12. Noble WC, Virani Z, Cree RGA (1992) Co-transfer of vancomycin and other resistance genes from Enterococcus faecalis NCTC12201 to Staphylococcus aureus. FEMS Microbiol. Lett 93: 195-198. » Pubmed

13. Pesewu GA, Cutler RR, Humber DP (2008) Antibacterial activity of plants used in traditional medicines of Ghana with particular reference to MRSA. J Ethnopharmacol 116: 102111. » CrossRef » Pubmed » Google Scholar

14. Peterson LR, Shanholzer CJ (1997) Tests for bactericidal effects of antimicrobial agents: technical performance and clinical relevance. Clin Microbiol Rev 5: 420-432.» CrossRef » Pubmed » Google Scholar
15. Roller S, Ernest N, Buckle J (2009) The antimicrobial activity of high-necrodane and other lavender oils on methicillin-sennsitive and -resistant Staphylococcus aureus (MSSA and MRSA). J Altern Complement Med 15: 275-279.

" CrossRef » Pubmed » Google Scholar

16. Rosato A, Vitali C, De Laurentis N, Armenise D, Antonietta MM (2007) Antibacterial effect of some essential oils administered alone or in combination with norfloxacin. Phytomedicine 14: 727-732. » CrossRef » Pubmed » Google Scholar

17. Shimizu M, Shiota S, Mizushima T, Ito H, Hatano T, et al. (2001) Marked potentiation of activity of beta-lactams against methicillin-resistant Staphylococcus aureus by corilagin, Antimicrob. Agents Chemother 45: 3198-201.

" CrossRef » Pubmed " Google Scholar

18. Silver L, Bostian K (1990) Screening of natural products for antimicrobial agents. Eur J Clin Microbiol Infect Dis 9: 455-461.» CrossRef » Pubmed » Google Scholar

19. Uehara Y, Nakama H, Agematsu K (2000) Bacterial interference among nasal inhabitants: eradication of Staphylococcus aureus from nasal carvities by artifical implantation of Corynebacterium. J Hosp Infect 44: 127-133. » CrossRef » Pubmed » Google Scholar

20. White RL, Burgess DS, Manduru M, Bosso JA (1996) Comparison of three different in vitro methods of detectiong synergy: time-kill, checkerboard, and E test, Antimicrob. Agents Chemother 40: 1914-1918. " CrossRef » Pubmed » Google Scholar

21. Xu HX, Lee SF (2001) Activity of plant flavonoids against antibiotic-resistant bacteria. Phytother Res 15: 39-43. " CrossRef » Pubmed » Google Scholar

22. Zuo GY, Meng FY, Hao XY, Zhang YL, Wang GC, et al. (2008) Antibacterial alkaloids from chelidonium majus linn (papaveraceae) against clinical isolates of methicillin-resistant Staphylococcus aureus. J Pharm Pharm Sci 11: 90-94. »CrossRef » Pubmed » Google Scholar 